CZASOPISMO INŻYNIERII LĄDOWEJ, ŚRODOWISKA I ARCHITEKTURY JOURNAL OF CIVIL ENGINEERING, ENVIRONMENT AND ARCHITECTURE

JCEEA, t. XXXIII, z. 63 (3/16), lipiec-wrzesień 2016, s. 461-468

Leszek STYSZKO ${ }^{1}$

Diana FIJAŁKOWSKA ${ }^{2}$

\title{
WPLYW ODMIAN I KLONÓW WIERZBY ORAZ GĘSTOŚCI SADZENIA NA PLON BIOMASY NA CELE ENERGETYCZNE W 8 ROKU UPRAWY
}

\begin{abstract}
Celem pracy była ocena plonowania 10 odmian i klonów wierzby w drugiej 4-letniej rotacji uprawianych na glebie lekkiej w warunkach gospodarki wodnej opadoworetencyjnej przy zróżnicowanym zagęszczeniu zrzezów podczas sadzenia (15020, 22134 i 33200 szt. ha ${ }^{-1}$ ). Doświadczenie składało się z okresu przygotowawczego (2007 rok) oraz dwóch 4-letnich okresów odrastania pędów (2008-2011 i 20122015). W ramach gęstości sadzenia rozlosowano siedem odmian (Start, Sprint, Turbo, Ekotur, Olof, Jorr i Tordis) oraz trzy klony wierzby wiciowej (1047, 1054 i 1047D). W drugiej 4-letniej rotacji wpływ gęstości sadzenia w odniesieniu do efektu przeciętnego oraz interakcji gęstości sadzenia $\mathrm{z}$ częstotliwością koszenia oraz z odmianami na plon świeżej i suchej masy pędów oraz na zawartość suchej masy w pędach był nieistotny. Odmiany wierzby różniły się plennością. Najwyższe plony uzyskano przy uprawie odmian Ekotur i Tordis (przeciętnie $15,60 \mathrm{Mg} \cdot \mathrm{ha}^{-1} \cdot \mathrm{rok}^{-1} \mathrm{~s} . \mathrm{m}$., niższe - przy odmianie Olof $\left(5,63 \mathrm{Mg} \cdot \mathrm{ha}^{-1} \cdot \mathrm{rok}^{-1} \mathrm{~s} . \mathrm{m}\right.$.), bardzo niskie - u odmian i klonów: 1047, 1054, 1047D, Sprint, Turbo i Jorr (przeciętnie 2,49 Mg. ha ${ }^{-1} \cdot \mathrm{rok}^{-1}$ s.m.), a najniższe - u odmiany Start $\left(0,38 \mathrm{Mg} \cdot \mathrm{ha}^{-1} \cdot \operatorname{rok}^{-1}\right.$ s.m.). Dwukrotne koszenie w pierwszej 4-letniej rotacji zmniejszyło plon suchej masy pędów w drugiej 4-letniej rotacji przeciętnie 2,7-krotnie u 10 genotypów, a u odmiany Ekotur 2-krotnie.
\end{abstract}

Słowa kluczowe: wierzba, odmiany, klony, gęstość sadzenia, biomasa, plon

\section{Wstęp}

Przy produkcji biomasy wierzbowej na cele energetyczne ważna jest obsada karp na hektarze w całym 25-letnim cyklu jej uprawy. Przy wieloletniej uprawie obsada karp na hektarze maleje w stosunku do pierwotnych nasadzeń. Zmniejszenie obsady karp wierzby na hektarze wpływa ograniczająco na plon biomasy pędów [1, 2, 7-9]. Zamieranie karp wierzby w 3-letnim cyklu przy uprawie na madzie bardzo ciężkiej w okolicach Kwidzyna, zależało od odmiany gęstości

\footnotetext{
${ }^{1}$ Autor do korespondencji / corresponding author: Leszek Styszko, Politechnika Koszalińska, 75-453 Koszalin, ul. Śniadeckich 2, (94) 3478-557, lstyszko@wbiis.tu.koszalin.pl

${ }^{2}$ Diana Fijałkowska, Politechnika Koszalińska, 75-453 Koszalin, ul. Śniadeckich 2, (94) 3486714, fijalkowska@wilsig.tu.koszalin.pl
} 
sadzenia oraz częstotliwości zbioru, jednakże nie przekraczało $10 \%$ obsady niezależnie od wariantu doświadczenia[7]. W badaniach autorów w latach 20072014 z 10 odmianami wierzby na zamieranie karp wierzby duży wpływ miał wiek uprawy, gęstość sadzenia zrzezów i ich współdziałanie, a mniejsze - odmiany i częstotliwość zbioru pędów w pierwszej 4-letniej rotacji [8]. Po czwartej wegetacji przeciętnie zamarło 6,6\% karp wierzby, a duży wzrost ilości martwych karp na poletku wystąpił w następnych wegetacjach $(6-20,7 \%$, $8-36,1 \%)$. Odmiany zakwalifikowano pod względem skłonności do zamierania: bardzo silne - Olof (22,9\%), silne - Start (19,0\%) i Jorr (17,9\%), średnie 1047 (13,2\%), 1054 (12,9\%), 1047D (12,8\%), Sprint (12,1\%), Turbo (11,8\%) i Tordis $(10,5 \%)$ oraz małe - Ekotur (6,5\%). Wzrost gęstości sadzenia zrzezów spowodowało nasilenie zamierania karp wierzby. Na obiektach z 1-krotnym koszeniem w pierwszej 4-letniej rotacji zamarło przeciętnie $12,2 \%$ karp, a przy 2-krotnym - 15,7\% [8].

Celem pracy była ocena plonowania 10 odmian i klonów wierzby w drugiej 4-letniej rotacji uprawianych na glebie lekkiej w warunkach gospodarki wodnej opadowo-retencyjnej przy zróżnicowanym zagęszczeniu zrzezów podczas sadzenia $\left(15020,22134\right.$ i 33200 szt. ha $\left.{ }^{-1}\right)$.

\section{Materiał i metody}

Doświadczenie polowe założono w Kościernicy pod Koszalinem $\left(16^{\circ} 24^{`} \mathrm{~N}\right.$ i $54^{\circ} 8^{\prime} \mathrm{E}$ ) metodą losowanych podbloków w układzie zależnym, w czterech powtórzeniach. Gleba pod doświadczeniem była lekka, klasy bonitacyjnej RIVaIVb, kompleksu żytniego dobrego, oznaczona została jako bielicowa właściwa pseudobielicowa o składzie piasku gliniastego lekkiego do głębokości $50-100 \mathrm{~cm}$, a głębiej - gliny lekkiej. Przed założeniem doświadczenia w analizach glebowych wykazano zawartość: próchnicy - $1,41 \%$ i przyswajalnych form makroskładników: $\mathrm{P}_{2} \mathrm{O}_{5}-16,5 \mathrm{mg} \cdot 100 \mathrm{~g}^{-1}, \mathrm{~K}_{2} \mathrm{O}-3,5 \mathrm{mg} \cdot 100 \mathrm{~g}^{-1} \mathrm{i} \mathrm{MgO}-1,7 \mathrm{mg} \cdot 100 \mathrm{~g}^{-1}$, a pH gleby wynosiło w warstwach: $0-20 \mathrm{~cm}-4,8$ i $21-40 \mathrm{~cm}-5,8$. Doświadczenie założono na polu, które przez 10 lat było nieużytkiem. W 2010 roku zamontowano $\mathrm{w}$ pobliżu doświadczenia dwa piezometry, gdzie poziom wody gruntowej był na głębokości 17,6-18,1 m pod powierzchnią gruntu.

Referowane doświadczenie składało się z okresu przygotowawczego (2007 rok) oraz dwóch 4-letnich okresów odrastania pędów (2008-2011 i 2012-2015). Na dużych poletkach (podbloki I rzędu) rozlosowano gęstości sadzenia zrzezów w 2007 roku: (a) $15020 \mathrm{szt} \cdot \mathrm{ha}^{-1}$, (b) $22134 \mathrm{szt} \cdot \mathrm{ha}^{-1}$, i (c) $33200 \mathrm{szt} \cdot \mathrm{ha}^{-1}$, a na małych poletkach (podbloki II rzędu) - siedem odmian wierzby wiciowej (Salix viminalis) (Start, Sprint, Turbo, Ekotur, Olof, Jorr i Tordis) oraz trzy klony wierzby wiciowej (1047, 1054 i 1047D). W kwietniu w latach 2008-2015 stosowano na całym doświadczeniu jednolicie nawożenie mineralne w czystym składniku: $\mathrm{N}$ $120 \mathrm{~kg} \cdot \mathrm{ha}^{-1}, \mathrm{P}-8,7 \mathrm{~kg} \cdot \mathrm{ha}^{-1}$ i K $-34,9 \mathrm{~kg} \cdot \mathrm{ha}^{-1}$. Na poletku o powierzchni $25,3 \mathrm{~m}^{2}$ wysadzono zrzezy w dwóch rzędach, przy czym każdy rząd $\left(12,65 \mathrm{~m}^{2}\right)$ zbierano 
oddzielnie. W pierwszej 4- letniej rotacji pędy na pierwszym rzędzie koszono 2-krotnie (18 XI 2010 - po 3 latach odrastania i 17 XI 2011 roku - po kolejnym 1-rocznym odrastaniu), a na drugim rzędzie - jednokrotnie (17 XI 2011 roku - po 4-roku odrastania). W drugiej 4- letniej rotacji pędy na pierwszym i drugim rzędzie skoszono pędy po 4-letnim okresie odrastania w tym samym dniu (2-4 XII 2015 roku). Próbki pędów do oznaczenia zawartości suchej masy pobrano w dniu koszenia. Dla badanych cech (plon świeżej i suchej masy pędów oraz zawartość suchej masy w pędach) wykonano standardową analizę wariancji i określono znaczenie komponentów wariancyjnych, a istotność efektów oceniono testem F.

\section{Wyniki i dyskusja}

We wszystkich latach wegetacja wierzby w latach rozpoczynała się w drugiej połowie kwietnia, a jej przebieg zależał od rozkładu temperatur i opadów. Dane o opadach oraz o współczynniku hydrotermicznym Sielianinowa w latach 2012-2015 zestawiono dla Koszalina według IMiGW w tabeli 1 [6]. W okresie badań w Koszalinie spadło od 588,9 mm w 2014 do $832 \mathrm{~mm}$ w 2012 roku opa$\mathrm{du}$, a podczas wegetacji wierzby (IV-X), od $387 \mathrm{~mm} \mathrm{w} 2014$ roku do $646 \mathrm{~mm}$ w 2007 roku (tab. 1).

Ze względu na nierównomierny rozkład opadów w miesiącach, charakterystyka przebiegu pogody na podstawie tego parametru była niewystarczająca. Hydrotermiczne warunki ekstremalne (skrajnie suche i bardzo suche oraz bardzo wilgotne i skrajnie wilgotne) oznaczone współczynnikiem Sielianinowa (K) mieszczą się w przedziałach $<0,7$ oraz $>2,5$. Za okres wegetacji współczynnik $\mathrm{K}$ obliczony jako średnia ważona, wahał się w granicach od 1,24 w 2014 roku do 2,01 w 2012 roku (tab. 2). Warunki skrajnie suche i bardzo suche wystąpiły w kwietniu 2012 roku, lipcu 2014 roku i sierpniu 2015 roku. Natomiast warunki bardzo wilgotne wystąpiły w kwietniu 2014 roku i w październiku 2012 roku, a skrajnie wilgotne w czerwcu 2015 roku.

Tabela 1. Opady [mm] w Koszalinie w latach 2012-2015 według IMiGW za GUS

Table 1. Precipitation [mm] in Koszalin in the 2012-2015 years according to Institute of Meteorology and Water Management and Central Statistical Office of Poland

\begin{tabular}{|c|c|c|c|c|}
\hline \multirow{2}{*}{ Miesiąc } & \multicolumn{4}{|c|}{ Opady w latach [mm] } \\
\cline { 2 - 5 } & 2012 & 2013 & 2014 & 2015 \\
\hline IV & 39 & 42,2 & 72,1 & 18,4 \\
\hline V & 16 & 51,1 & 52,5 & 37,3 \\
\hline VI & 89 & 64,4 & 55,9 & 144,7 \\
\hline VII & 119 & 54,5 & 37,9 & 96,3 \\
\hline VIII & 100 & 52,3 & 83,6 & 13,3 \\
\hline IX & 103 & 85,4 & 54,4 & 67,1 \\
\hline X & 71 & 44,3 & 30,6 & 28,5 \\
\hline Suma IV-X & 537,0 & 394,2 & 387,0 & 405,6 \\
\hline Suma I-XII & 832,0 & 615,9 & 588,9 & 683,9 \\
\hline
\end{tabular}


Tabela 2. Współczynnik hydrotermiczny Sielianinowa w Koszalinie w latach 2012-2015

Table 2. Sielianinow hydrothermal coefficient in Koszalin in the 2012-2015 years

\begin{tabular}{|c|c|c|c|c|}
\hline \multirow{2}{*}{ Miesiąc } & \multicolumn{4}{|c|}{ Współczynnik Sielianinowa (K) w latach } \\
\cline { 2 - 5 } & 2012 & 2013 & 2014 & 2015 \\
\hline IV & 1,73 & 2,07 & 2,50 & 0,83 \\
\hline V & 0,39 & 1,19 & 1,37 & 1,06 \\
\hline VI & 1,99 & 1,37 & 1,23 & 3,42 \\
\hline VII & 2,18 & 0,98 & 0,59 & 1,79 \\
\hline VIII & 1,85 & 0,93 & 1,56 & 0,21 \\
\hline IX & 2,42 & 2,21 & 1,19 & 1,56 \\
\hline $\mathbf{X}$ & 2,60 & 1,36 & 0,88 & 1,09 \\
\hline $\begin{array}{c}\text { Średnia ważona } \\
\text { IV-X }\end{array}$ & 2,01 & 1,34 & 1,24 & 1,42 \\
\hline
\end{tabular}

Strukturę procentową efektów głównych oraz ich interakcji w odniesieniu do udziału w zmienności całkowitej plonu świeżej i suchej masy pędów oraz zawartości w nich suchej masy zestawiono w tabeli 3 .

Tabela 3. Wpływ badanych czynników na plon pędów wierzby i zawartość suchej masy

Table 3. Impact of examined factors on the yield of willow shoots and dry matter content

\begin{tabular}{|c|c|c|c|c|}
\hline \multirow[b]{2}{*}{ Komponent wariancyjny } & \multirow{2}{*}{$\begin{array}{l}\text { Poziomy } \\
\text { czynnika }\end{array}$} & \multicolumn{3}{|c|}{$\begin{array}{c}\text { Struktura procentowa komponetów } \\
\text { wariancyjnych }\end{array}$} \\
\hline & & $\begin{array}{l}\text { Plon świeżej } \\
\text { masy pędów }\end{array}$ & $\begin{array}{l}\text { Zawartość su- } \\
\text { chej masy } \\
\text { w pędach }\end{array}$ & $\begin{array}{l}\text { Plon suchej } \\
\text { masy pędów }\end{array}$ \\
\hline Rzędy na poletku [A] & 2 & $15,8 * * *$ & 0,8 & $17,1 * * *$ \\
\hline Gęstość sadzenia zrzezów [B] & 3 & 0,4 & 2,7 & 0,5 \\
\hline Odmiany i klony wierzby [C] & 10 & $47,7 * * *$ & $35,5 * * *$ & $54,1 * * *$ \\
\hline Suma współdziałań & & 11,7 & 3,8 & 2,0 \\
\hline AxB & & 0,0 & 0,0 & 0,0 \\
\hline CxB & & 0,2 & 0,3 & 0,1 \\
\hline $\mathrm{CxA}$ & & $11,5^{* * *}$ & 3,5 & $1,9 * * *$ \\
\hline CxBxA & & 0,0 & 0,0 & 0,0 \\
\hline Czynnik losowy (bloki) & 4 & 24,4 & 57,2 & 26,3 \\
\hline Suma & - & 100,0 & 100,0 & 100,0 \\
\hline Suma ocen zmienności & - & 2373,4 & 14,66 & 498,1 \\
\hline
\end{tabular}

Istotność różnic przy: $* * * \alpha=0,001$

W analizach wykazano dominujące znaczenie odmian i klonów wierzby, a duże znaczenie - rzędów na poletku, a bardzo mały efekt - gęstości sadzenia. Znaczenie rzędów na poletku wiąże się z częstotliwością zbioru w pierwszej 4-letniej rotacji, a mianowicie na I rzędzie każdego poletka dokonano 2-krotnie zbioru w odstępie 1 roku (listopad 2010 i 2011 roku), a na II rzędzie koszono tylko 1-krotnie (listopad 2011 roku, tzn. po 4. roku odrastania pędów). 
Tabela 4. Wpływ badanych czynników na plon świeżej i suchej biomasy pędów oraz na zawartość suchej masy w pędach wierzby

Table 4. Impact of examined factors on the yield of fresh and dry biomass of shoots and dry matter content in the shoots of willow

\begin{tabular}{|c|c|c|c|c|c|}
\hline \multirow[t]{2}{*}{ Czynniki } & \multirow{2}{*}{$\begin{array}{l}\text { Poziomy } \\
\text { czynnika }\end{array}$} & \multirow{2}{*}{ 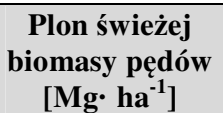 } & \multirow{2}{*}{$\begin{array}{c}\text { Zawartość su- } \\
\text { chej masy w } \\
\text { pędach [\%] }\end{array}$} & \multicolumn{2}{|c|}{$\begin{array}{l}\text { Plon suchej biomasy } \\
\text { pędów }\left[\mathrm{Mg}^{-} \mathrm{ha}^{-1}\right]\end{array}$} \\
\hline & & & & na 4 lata & na 1 rok \\
\hline \multirow{3}{*}{$\begin{array}{l}\text { Rzędy na po- } \\
\text { letku [A] }\end{array}$} & I & $16,3 \mathrm{a}$ & $44,1 \mathrm{a}$ & 7,6 & 1,90 \\
\hline & II & $44,1 \mathrm{~b}$ & $44,7 \mathrm{a}$ & 20,8 & 5,20 \\
\hline & $\mathrm{NIR}_{0,05}$ & $10,3 * * *$ & $1,0 \mathrm{n} . \mathrm{i}$ & $4,9 * * *$ & - \\
\hline \multirow{4}{*}{$\begin{array}{l}\text { Gęstość sa- } \\
\text { dzenia zrze- } \\
\text { zów w tys. } \\
\text { sztuk· ha }{ }^{-1}[B]\end{array}$} & 15020 & $24,1 \mathrm{a}$ & $43,7 \mathrm{a}$ & 11,3 & 2,83 \\
\hline & 22134 & $32,9 a$ & $44,6 \mathrm{a}$ & 15,5 & 3,88 \\
\hline & 33200 & $33,6 \mathrm{a}$ & $45,1 \mathrm{a}$ & 15,9 & 3,98 \\
\hline & $\mathrm{NIR}_{0,05}$ & $12,6 \mathrm{n} . \mathrm{i}$ & $1,4 \mathrm{n} . \mathrm{i}$ & 5,9 n.i & - \\
\hline \multirow{11}{*}{$\begin{array}{l}\text { Odmiany } \\
\text { i klony } \\
\text { wierzby [C] }\end{array}$} & 1047 & $13,4 \mathrm{a}$ & $42,4 a$ & $5,8 \mathrm{ab}$ & 1,45 \\
\hline & 1054 & $12,4 \mathrm{a}$ & $42,7 \mathrm{a}$ & $5,5 \mathrm{ab}$ & 1,38 \\
\hline & 1047D & $15,3 \mathrm{a}$ & $42,1 \mathrm{a}$ & $6,7 \mathrm{a}$ & 1,68 \\
\hline & Start & $1,9 \mathrm{~b}$ & $42,7 \mathrm{a}$ & $0,8 b$ & 0,20 \\
\hline & Sprint & $11,2 \mathrm{ab}$ & $43,2 a$ & $4,9 \mathrm{ab}$ & 1,22 \\
\hline & Turbo & $12,4 \mathrm{ab}$ & $45,5 b$ & $5,8 \mathrm{ab}$ & 1,45 \\
\hline & Ekotur & $95,6 c$ & $49,1 \mathrm{c}$ & $47,5 \mathrm{c}$ & 11,88 \\
\hline & Olof & $31,8 \mathrm{~d}$ & $46,5 d$ & $15,2 \mathrm{~d}$ & 3,80 \\
\hline & Jorr & $18,0 \mathrm{a}$ & $43,7 \mathrm{ab}$ & $8,1 \mathrm{a}$ & 2,03 \\
\hline & Tordis & $90,1 c$ & $46,4 d$ & 41,9d & 10,48 \\
\hline & $\mathrm{NIR}_{0,05}$ & $10,9 * * *$ & $1,6^{* * *}$ & $5,2 * * *$ & - \\
\hline $\begin{array}{l}\text { Średnia do- } \\
\text { Świadczenia }\end{array}$ & - & 30,2 & 44,4 & 14,2 & 3,55 \\
\hline
\end{tabular}

Istotność różnic przy: $* * * \alpha=0,001 ;$ n.i. - brak istotności; a, b, c, d . . grupy jednorodne

$\mathrm{W}$ analizach przy plonie biomasy pędów miała miejsce wysoko istotna interakcja odmian i klonów wierzby z rzędami, co jest związane $\mathrm{z}$ reakcją odmian i klonów wierzby na częstotliwość koszenia w pierwszej 4-letniej rotacji (tab. 5). $\mathrm{W}$ badaniach nie udowodniono istotności interakcji odmian i klonów wierzby z gęstością sadzenia zrzezów (tab. 3). Odmiany różniły się plennością. Najwyższe plony uzyskano przy uprawie odmian Ekotur i Tordis, niższe - przy odmianie Olof, bardzo niskie - u odmian i klonów: 1047, 1054, 1047D, Sprint, Turbo i Jorr, a najniższe - u odmiany Start (tab. 4). Odmiana Ekotur charakteryzowała się także najwyższą zawartością suchej masy w pędach (tab. 4). U wszystkich odmian i klonów plony pędów były istotnie niższe na I rzędzie niż na II rzędzie (tab. 5), co wskazuje, że zbyt częste koszenie w pierwszej 4-letniej rotacji obniżało plonowanie wierzby w drugiej 4-letbniej rotacji. W tabeli 5 utworzono grupy jednorodne odmian i klonów wierzby w ramach I oraz II rzędu na poletku, a przy plonie suchej biomasy pędów dodatkowo przeliczono wydajność na 1 rok wegetacji. 
Tabela 5. Plon świeżej i suchej masy pędów w rzędach na poletku $\left[\mathrm{Mg} \cdot \mathrm{ha}^{-1}\right]$

Table 5. The yield of fresh and dry mass of shoots in rows on the plot $\left[\mathrm{Mg} \cdot \mathrm{ha}^{-1}\right]$

\begin{tabular}{|c|c|c|c|c|c|c|}
\hline \multirow{3}{*}{$\begin{array}{c}\text { Odmiany } \\
\text { i klony } \\
\text { wierzby }[\mathrm{C}]\end{array}$} & \multicolumn{2}{|c|}{$\begin{array}{l}\text { Plon świeżej biomasy } \\
\text { pędów na rzędach po- } \\
\text { letka }\left[\mathrm{Mg}^{\left.-1 \mathrm{ha}^{-11}\right]}\right.\end{array}$} & \multicolumn{4}{|c|}{$\begin{array}{c}\text { Plon suchej biomasy pędów na rzędach po- } \\
\text { letka }\left[\mathrm{Mg}^{\cdot} \mathrm{ha}^{-1}\right]\end{array}$} \\
\hline & I & II & I & II & I & II \\
\hline & \multicolumn{2}{|c|}{ na 4 lata } & \multicolumn{2}{|c|}{ na 4 lata } & \multicolumn{2}{|c|}{ na 1 rok } \\
\hline 1047 & $3,9 \mathrm{ac}$ & $22,9 \mathrm{a}$ & $1,6 \mathrm{a}$ & $9,9 \mathrm{a}$ & 0,40 & 2,48 \\
\hline 1054 & $4,6 \mathrm{ac}$ & $20,3 a$ & $1,9 \mathrm{a}$ & $9,2 \mathrm{a}$ & 0,48 & 2,30 \\
\hline 1047D & $6,2 \mathrm{ac}$ & $24,4 a$ & $2,6 \mathrm{a}$ & $10,7 \mathrm{a}$ & 0,65 & 2,68 \\
\hline Start & $0,2 \mathrm{a}$ & $3,5 b$ & $0,1 \mathrm{a}$ & $1,5 \mathrm{~b}$ & 0,03 & 0,38 \\
\hline Sprint & $3,0 \mathrm{ac}$ & $19,4 b$ & $1,4 \mathrm{a}$ & $8,5 \mathrm{ab}$ & 0,35 & 2,12 \\
\hline Turbo & $5,8 \mathrm{ac}$ & $18,9 \mathrm{ab}$ & $2,8 \mathrm{a}$ & $8,8 \mathrm{ab}$ & 0,70 & 2,20 \\
\hline Ekotur & $65,5 b$ & $125,7 \mathrm{c}$ & $31,7 \mathrm{~b}$ & $63,3 \mathrm{c}$ & 7,93 & 15,83 \\
\hline Olof & $17,0 \mathrm{c}$ & $46,5 \mathrm{~d}$ & $7,9 \mathrm{c}$ & $22,5 \mathrm{~d}$ & 1,98 & 5,63 \\
\hline Jorr & $8,4 \mathrm{ac}$ & $27,6 \mathrm{e}$ & $3,6 \mathrm{a}$ & $12,6 \mathrm{a}$ & 0,90 & 3,15 \\
\hline Tordis & $48,5 d$ & $131,7 \mathrm{c}$ & $22,5 d$ & $61,4 \mathrm{c}$ & 5,62 & 15,35 \\
\hline $\mathrm{NIR}_{0,05}$ & \multicolumn{2}{|c|}{$15,4 * *$} & \multicolumn{2}{|c|}{$7,4^{* *}$} & - & - \\
\hline
\end{tabular}

**Istotność różnic przy $\alpha=0,01 ; \mathrm{a}, \mathrm{b}, \mathrm{c}, \mathrm{d}$. . grupy jednorodne w ramach rzędu poletka

Przedstawione badania dotyczą uprawy wierzby na glebie lekkiej o gospodarce wodnej typu opadowo-retencyjnego, gdzie poziom wody gruntowej jest na głębokości 17,6-18,1 m pod powierzchnią gruntu. Z powodu występowania w latach 2012-2015 w kilku miesiącach warunków ekstremalnie i bardzo suchych, uzyskano niższe plony suchej biomasy pędów niż podaje to literatura krajowa $[3,5,7,9,10]$ oraz zagraniczna $[1,2,4,11]$. W badaniach Matyki [5] wysoki poziom wody gruntowej na glebie lekkiej (2,0-2,5 m od powierzchni gruntu) spowodowały brak zróżnicowania plonów wierzby na glebach ciężkiej (kompleks 8) i lekkiej (kompleks 5). W badaniach własnych mimo niekorzystnych warunków uprawy, wykazano że odmiany Ekotur i Tordis przy koszeniu co 4 lata wydały ponad $15 \mathrm{Mg} \cdot \mathrm{ha}^{-1} \cdot \mathrm{rok}^{-1}$ s.m.. Te same odmiany, które były koszone w pierwszej 4-letniej rotacji dwukrotnie w odstępie jednego roku, dały plon niższy odpowiednio o 50,0\% i 63,4\%. Utworzono grupy jednorodne genotypów wierzby pod względem plonowania. Najwyższy plon uzyskano u odmian Ekotur i Tordis (przeciętnie 15,6 Mg.ha ${ }^{-1} \cdot \operatorname{rok}^{-1}$ s.m.), średni u odmiany Olof (5,63 Mg. ha ${ }^{-1} \cdot \operatorname{rok}^{-1}$ s.m.), bardzo niski u klonów i odmian: 1047, 1054, 1047D, Sprint, Turbo i Jorr $\left(2,49 \mathrm{Mg} \cdot \mathrm{ha}^{-1} \cdot \mathrm{rok}^{-1} \mathrm{~s} . \mathrm{m}\right.$.) i ekstremalnie niski u odmiany Start $\left(0,38 \mathrm{Mg} \cdot \mathrm{ha}^{-1} \cdot \mathrm{rok}^{-1}\right.$ s.m. $)$. Przy koszeniu pędów dwukrotnie w odstępie jednego roku w pierwszej 4-letniej rotacji, te same odmiany wydały plon niższy, a odmiany uszeregowano następująco $\mathrm{w}$ grupy jednorodne: najwyższy plon uzyskano u odmian Ekotur (przeciętnie 7,93 Mg.ha ${ }^{-1} \cdot \mathrm{rok}^{-1} \mathrm{~s} . \mathrm{m}$.), średni u odmiany Tordis (5,62 Mg.ha ${ }^{-1} \cdot \operatorname{rok}^{-1}$ s.m.), bardzo niski u odmiany Olof $\left(1,98 \mathrm{Mg} \cdot \mathrm{ha}^{-1} \cdot \operatorname{rok}^{-1}\right.$ s.m.) i ekstremalnie niski u klonów i odmian: 1047, 1054, 1047D, Start, Sprint, Turbo i Jorr $\left(0,50 \mathrm{Mg} \cdot \mathrm{ha}^{-1} \cdot \mathrm{rok}^{-1}\right.$ s.m. $)$. W drugiej 4-letniej 
rotacji nie udowodniono wpływu na plon suchej masy gęstości sadzenia w odniesieniu do efektu przeciętnego oraz interakcji z rzędami na poletku oraz z odmianami. Wykazano tylko tendencję do wzrostu plonu przy sadzeniu 22134 zrzezów i 33200 zrzezów na hektarze w stosunku do obsady 15020 zrzezów. Dane te potwierdzają doniesienia z literatury, że na uprawach produkcyjnych powinno się wysadzać $20-25$ tysięcy zrzezów wierzby na hektarze [7,11] i kosić 1-krotnie w 3- lub 4-letnim cyklu odrastania.

\section{Wnioski}

1. W warunkach gleby lekkiej o gospodarce wodnej typu opadoworetencyjnego, największy wpływ na plonowanie wierzby miały odmiany i klony wierzby, częstotliwość koszenia pędów oraz współdziałanie genotypów z częstotliwością koszenia pędów w pierwszej 4-letniej rotacji.

2. W drugiej 4-letniej rotacji wpływ gęstości sadzenia w odniesieniu do efektu przeciętnego oraz interakcji gęstości sadzenia z częstotliwością koszenia oraz z odmianami na plon suchej masy pędów był nieistotny.

3. Odmiany wierzby różniły się plennością. Najwyższe plony uzyskano przy uprawie odmian Ekotur i Tordis, niższe - przy odmianie Olof, bardzo niskie u odmian i klonów: 1047, 1054, 1047D, Sprint, Turbo i Jorr, a najniższe u odmiany Start.

4. Dwukrotne koszenie w pierwszej 4-letniej rotacji zmniejszyło plon suchej masy pędów w drugiej 4-letniej rotacji przeciętnie 2,7 krotnie u 10 genotypów, a u odmiany Ekotur 2-krotnie.

\section{Literatura}

[1] Bullard M.J., Mustil S.J., McMillan S.D., Nixon P.M.I., Carver P., Britt C.P.: Yield improvements through modification of planting density and harvest frequency in short rotation coppice Salix spp. -1. Yield response in two morphological diverse warieties. Biomass Bioenergy. 22, 2002, pp. 15-25.

[2] Caslin B., Finnan J., McCracken A.: Short Rotation Coppice Willow Best Practice Guidelines. Teagas AFBI, Belfast 2010.

[3] Kuś J., Matyka M.: Wydajność wybranych gatunków roślin uprawianych na cele energetyczne w zależności od jakości gleby. Fragm. Agron. 26(4), 2009, s. 103-110.

[4] Lebresque M., Teodorescu T. I.: Field performance and biomass production of 12 willow and poplar clones in short-rotation coppice in southern Quebec (Canada). Biomass Bioenergy 29, 2005, pp. 1-9.

[5] Matyka M. 2013. Produkcyjne i ekonomiczne aspekty uprawy roslin na cele energetyczne. Rozpr. hab. Wydawnictwo IUNG-PIB Monogr. Rozpr. 35, Puławy, ss. 98.

[6] GUS 2015. Ochrona środowiska. www.stat.gov.pl \{dostęp 06.05.2016 r.\}.

[7] Stolarski J.M.: Agrotechniczne i ekonomiczne aspekty produkcji biomasy wierzby krzewiastej (Salix spp.) jako surowca energetycznego, Wydawnictwo Uniwersytetu Warmińsko-Mazurskiego, Olsztyn, 2009, ss.145. 
[8] Styszko L., Fijałkowska D.: Influence of varieties and clones and planting density on dying out willow bushes in a 8-year. Wpływ odmian i klonów oraz gęstości sadzenia na zamieranie karp wierzby krzewiastej w 8-letnim cyklu uprawy. Progress in Plant Protection 55 (4), 2015, s. 488-493.

[9] Szczukowski S., Tworkowski J.: Produktywność oraz wartość energetyczna biomasy wierzb krzewiastych Salix sp. na różnych typach gleb w pradolinie Wisły. Post. Nauk Rol. 2, 2001, s. 29-38.

[10] Szczukowski S., Tworkowski J., Stolarski M., Fortuna W.: Plon biomasy wierzby pozyskanej w krótkich rotacjach zbioru na plantacji przemysłowej. Fragm. Agron. 26(3), 2009, s. 146-155.

[11] Wilkinson J.M., Evans E.J., Bilsborrow P.E., Wright C., Hewison W.O., Pillbeam D.J.: Yield of willow cultivars at different planting densites in a commercial short rotation coppice in the north of England. Biomass Bioener. 31, 2007, s. 469-474.

\title{
IMPACT OF VARIETIES, CLONES AND PLANTING DENSITY OF WILLOW ON YIELD OF BIOMASS FOR ENERGY PURPOSES DURING $8^{\text {TH }}$ YEAR OF CULTIVATION
}

\begin{abstract}
S u m m a r y
The aim of the study was to evaluate the yield of 10 varieties and clones of willow in the second 4-year rotation, cultivated on light soil under rainfall water-retention conditions, at various density of cuttings planting $(15,020,22,134$ and 33,200 pieces per hectare). The experiment consisted of a preparatory period (year 2007) and two 4-year periods of shoots regrowth (2008-2011 and 2012-2015). Seven varieties (Start, Sprint, Turbo, Ekotur, Olof, Jorr and Tordis) and three clones (1047, 1054 and 1047D) were drawn within densities of planting. During the second 4-year rotation impact of planting density with respect to the average effect and to the interaction of density of planting with the cutting frequency and varieties on the yield of fresh and dry mass of shoots and the content of dry matter in the shoots was insignificant. Willow varieties differed in fertility. The highest yields were obtained during cultivation of Ekotur and Tordis varities (on average $15.60 \mathrm{Mg} \cdot \mathrm{ha}^{-1} \cdot \mathrm{yr}^{-1}$ of dry matter), lower for Olof variety (5.63 Mg.ha ${ }^{-1} \cdot \mathrm{yr}^{-1}$ of dry matter), very low - for 1047, 1054, 1047D clones and Sprint, Turbo and Jorre varieties (an average of $2.49 \mathrm{Mg} \cdot \mathrm{ha}^{-1} \cdot \mathrm{yr}^{-1}$ of dry matter), and the lowest for Start variety $\left(0.38 \mathrm{Mg} \cdot \mathrm{ha}^{-1} \cdot \mathrm{yr}^{-1}\right.$ of dry matter). Double mowing during the first 4-years rotation decreased yield of dry mass of shoots during of the second 4-year rotation 2.7 times on the average for 10 genotypes and 2 times for Ekotur variety.
\end{abstract}

Keywords: willow, cultivars, clones, planting density, biomass, yield

DOI: $10.7862 / \mathrm{rb} .2016 .229$

Przestano do redakcji: $16.05 .2016 r$.

Przyjęto do druku: 30.11 .2016 r. 